\title{
АКТУАЛЬНОСТЬ УДАЛЕНИЯ НЕВУСА ЯДАССОНА У ЛИЦ МОЛОДОГО ВОЗРАСТА
}

\author{
Т. А. Гайдина ${ }^{1,2 凶, ~ А . ~ С . ~ Д в о р н и к о в ~}{ }^{1}$, П. А. Скрипкина ${ }^{1}$, Г. Б. Арутюнян ${ }^{1}$ \\ ${ }^{1}$ Кафеедра дерматовенерологии, лечебный факультет, Российский национальный исследовательский медицинский университет имени Н. И. Пирогова, Москва \\ 2 ООО Компания РЕДНОР, Москва
}

Одним из доброкачественных образований кожи является себорейный невус Ядассона (NSJ) - гамартома, локализующаяся преимущественно на коже лица или волосистой части головы и одинаково часто встречающаяся у мужчин и женщин. Плюрипотентные первичные эпителиальные клетки, входящие в структуру NSJ, являются благоприятной средой для развития на его фоне как доброкачественных, так и злокачественных опухолей. Для исключения неопластической трансформации целесообразно удалять NSJ сразу после полового созревания. При невозможности хирургического вмешательства пациентам требуется постоянное динамическое наблюдение. В данной работе представлено два случая успешного удаления $\mathrm{CO}_{2}$-лазером NSJ у пациентов молодого возраста.

Ключевые слова: невус себорейный Ядассона, доброкачественные образования кожи, злокачественная трансформация невуса, удаление $\mathrm{CO}_{2}$-лазером

$\triangle$ Для корреспонденции: Гайдина Татьяна Анатольевна ул. Островитянова, д. 1, г. Москва, 117997; doc429@yandex.ru

Статья получена: 05.05.2018 Статья принята к печати: 12.07 .2018

DOI: $10.24075 /$ vrgmu.2018.033

\section{RATIONALE FOR REMOVING NEVUS SEBACEUS OF JADASSOHN IN YOUNG PATIENTS}

\author{
Gaydina $T A^{1,2} \otimes$, Dvornikov $A S^{1}$, Skripkina $\mathrm{PA}^{1}$, Arutyunyan $\mathrm{GB}^{1}$ \\ ${ }^{1}$ Department of Dermatology and Venereology, Faculty of General Medicine, Pirogov Russian National Research Medical University, Moscow \\ ${ }^{2}$ REDNOR OOO, Moscow
}

Nevus sebaceous of Jadassohn (NSJ) is a benign skin lesion, a hamartoma typically localized to the face or scalp and equally common in men and women. Pluripotent epithelial cells that give rise to NSJ provide a favorable environment for benign and malignant tumors to form in the nevus. Because of the possibility of malignant transformation, NSJ should be removed after puberty. If surgery is impossible, long-term observation is indicated. In this work we present two cases of successful NSJ treatment with the $\mathrm{CO}_{2}$ laser in young patients.

Keywords: nevus sebaceus of Jadassohn, benign skin lesion, malignant nevus transformation, $\mathrm{CO}_{2}$ laser treatment

$\triangle$ Correspondence should be addressed: Tatiana A. Gaydina

Ostrovityanova 1, 117997; doc429@yandex.ru

Received: 05.05.2018 Accepted: 12.07.2018

DOI: 10.24075/brsmu.2018.033

В 1895 г. немецкий дерматовенеролог Joseph Jadassohn впервые описал гамартому сальных желёз [1]. Невус сальных желёз Ядассона (син.: Nevus sebaceous Jadassohn, NSJ, невус сальных желёз, себорейный невус) - врожденный органоидный невус, локализующийся преимущественно на коже лица или волосистой части головы и одинаково часто встречающийся у лиц обоего пола (рис. 1). Развитие невуса обусловлено пролиферацией и мальформацией сальных желёз и является результатом дифференцировки плюрипотентных клеток в сторону зрелых сальных и апокриновых структур [2]. Клинически NSJ представлен бессимптомной солитарной слегка приподнятой над уровнем кожи бляшкой округлой или линейной формы размером до 10 см и имеет мелкие полушаровидные папулы розового, желтого или коричневого цвета с гладкой или папилломатозной поверхностью. Для NSJ характерны возрастные особенности, связанные с дифференцировкой сальных и потовых желёз [3]. У детей раннего возраста невус лишен волос, малозаметен и имеет гладкую или слабовыраженную сосочковую поверхность. В период полового созревания NSJ становится более выпуклым, покрывается тесно прилегающими друг к другу папулами, цвет которых варьирует от светло-желтого до темно-коричневого. При гистологическом исследовании NSJ у пациентов старшего возраста можно обнаружить неправильное формирование эпидермиса и долек зрелых сально-волосяных фролликулов, большое количество различных эпителиальных структур (расширенные апокриновые железы, абортивные волосяные фолликулы) [4]. У лиц подросткового возраста встречаются скопления недифференцированных клеток, напоминающие очаги базалиомы [2].

В данной работе описаны два клинических случая удаления невуса сальных желёз Ядассона с использованием $\mathrm{CO}_{2}$-лазера. 


\section{Описание клинических случаев}

Случай 1

Пациент К., мужчина, 18 лет, обратился в клинику с жалобами на образование, локализованное на коже левой половины спинки носа (рис. 2). Анамнез: образование было у пациента с рождения. В период полового созревания он стал отмечать его незначительный рост и скудное отделяемое светло-жёлтого цвета, появляющееся при надавливании. Молодой человек неоднократно пытался самостоятельно выдавить и удалить раздражающее его образование. Год назад в центре образования появился вырост, который в течение последних 6 месяцев увеличился до 0,5 см (рис. 3). Status localis: кожный покров лица нормальной окраски, в Т-образной зоне наблюдается избыточное салоотделение, комедоны закрытого типа. На коже левой половины спинки носа папулы, сливающиеся в продолговато-овальную бляшку размером 0,5 × 0,8 см светло-розового цвета, имеющую дольчатое строение и незначительно возвышающуюся над уровнем кожи. В центре образования расположен вырост цилиндрической формы 0,1 × 0,1 см в основании и 0,5 см высотой. На верхушке выроста плотные слоистые роговые массы. При пальпации образование мягкое, безболезненное. Гистологическое исследование: выявлены папилломатозная эпидермальная гиперплазия и гиперплазия сальных желез. Клинический диагноз: D23.3, себорейный невус Ядассона, кожный рог. С учётом локализации и небольшого размера образования было принято решение об удалении образования $\mathrm{CO}_{2}$-лазером под местной анестезией. Осмотр через 2 недели после удаления показал формирование нормотрофического рубца (рис. 4)

\section{Случай 2}

Пациенка А., женщина, 30 лет, обратилась в клинику с целью эстетической коррекции образования на коже лба (рис. 5). Анамнез: образование было у пациентки с рождения. В период полового созревания образование незначительно увеличилось в объеме, стало более выступающим над поверхностью кожи и приобрело более тёмный цвет. За последние десять лет никаких изменений пациентка не отмечала. Status localis: кожный покров лица нормальной окраски. На коже лба имеются папулы, сливающиеся в продолговато-овальную бляшку размером 1,7 × 1,1 см светло-коричневого цвета с бугристой поверхностью. Образование характеризуется дольчатым строением и незначительно возвышается над уровнем кожи. При пальпации мягкое, безболезненное. Гистологическое исследование: выявлена субэпителиальная пролиферация сальных желез (рис. 6). Клинический диагноз: D23.3, себорейный невус Ядассона. У пациентки под местной анестезией проведено удаление образования $\mathrm{CO}_{2}$-лазером. Осмотр через 2 недели после удаления показал формирование нормотрофического рубца (рис. 7).

\section{Обсуждение клинических случаев}

Существуют разные мнения по поводу сроков и целесообразности удаления NSJ. До полового созревания NSJ, как правило, малозаметен. После полового созревания в NSJ происходит развитие вторичных доброкачественных новообразований с частотой 10-30\% [5]. В литературе описаны различные доброкачественные опухоли, развившиеся

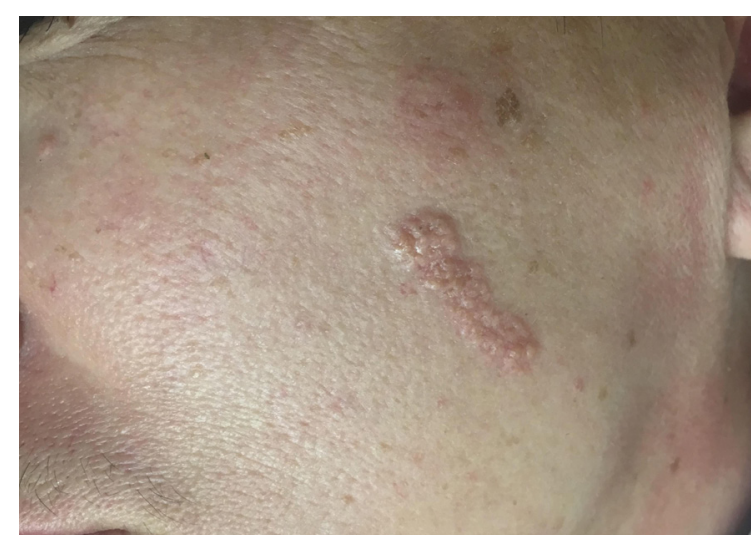

Рис. 1. Себорейный невус Ядассона на коже щеки у женщины 35 лет

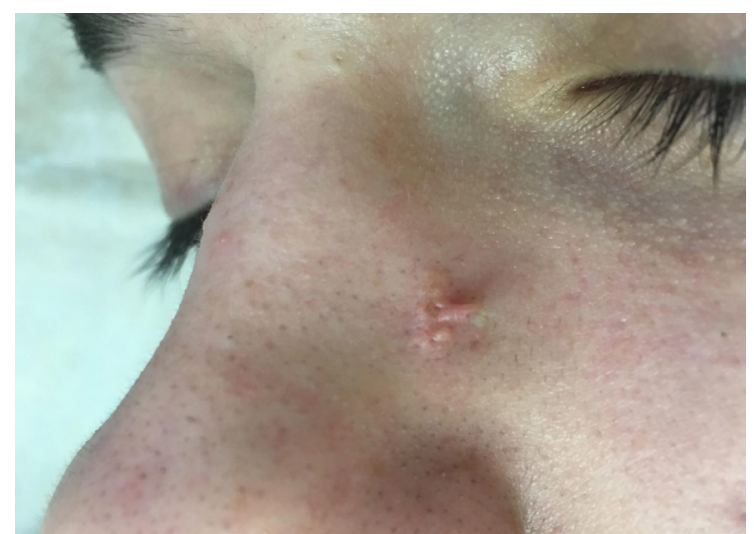

Рис. 2. Пациент К., 18 лет. Себорейный невус Ядассона с кожным рогом на коже спинки носа. Вид сбоку

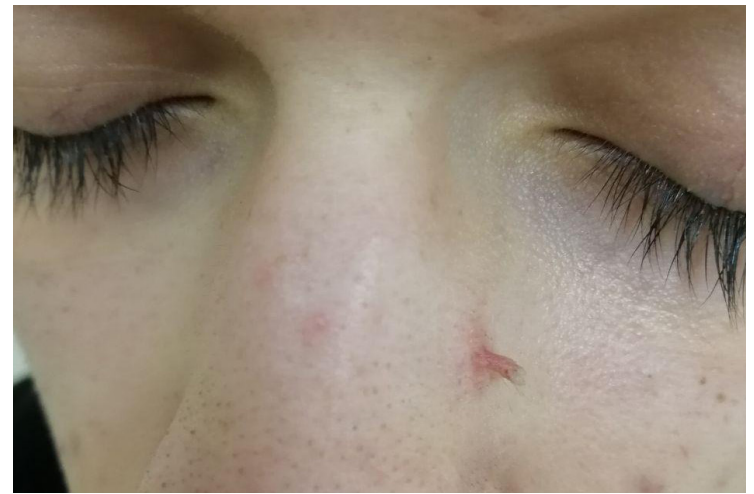

Рис. 3. Тот же пациент. Себорейный невус Ядассона с кожным рогом на коже спинки носа. Вид спереди

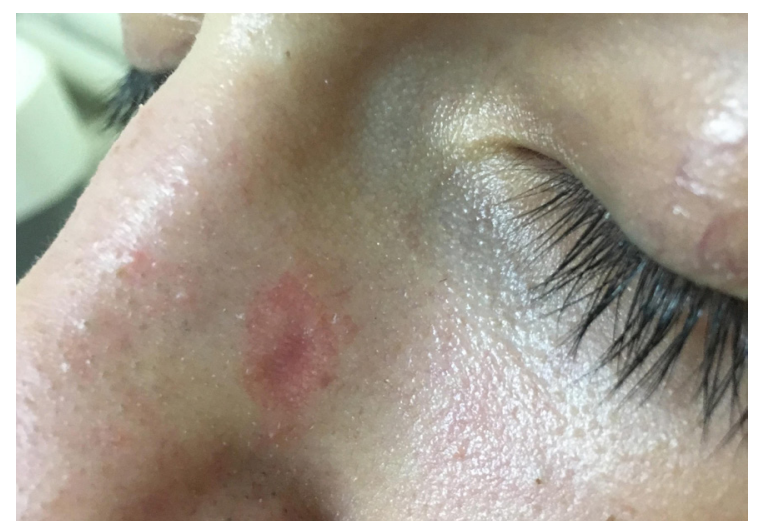

Рис. 4. Тот же пациент. Формирование нормотрофического рубца после удаления невуса Ядассона $\mathrm{CO}_{2}$-лазером 


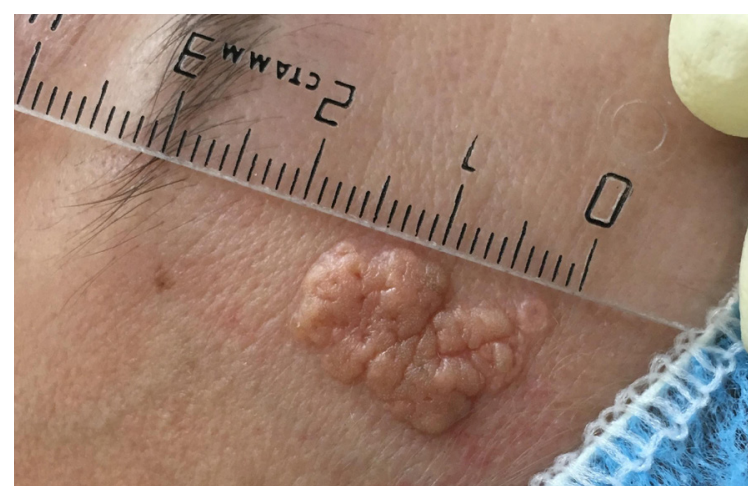

Рис. 5. Пациентка А., 30 лет. Себорейный невус Ядассона на коже лба

в NSJ, из которых наиболее часто встречаются трихобластома и сирингоцистаденома [6]. Такая трансформация NSJ приносит пациентам дополнительный дискомфорт и требует эстетической коррекции. Развитие кожного рога на фоне NSJ - редкое явление $[7,8]$. Точных статистических данных о частоте злокачественной трансформации NSJ нет. Редкость злокачественной трансформации отмечают отечественные исследователи [2] и некоторые зарубежные источники [9]. Другие авторы указывают на злокачественную трансформацию в 22\% случаев [10], большинство из которых описаны у пациентов старше 50 лет $[11,12]$. Доказано, что риск злокачественной трансформации увеличивается с возрастом [11]. Описаны случаи развития множественных новообразований в пределах одного и того же NSJ у лиц старше 50 лет [13]. Типичная локализация NSJ на коже лица и волосистой части головы также служит одним из факторов риска перерождения в злокачественный тип опухоли. Клеточная структура NSJ (плюрипотентные первичные эпителиальные клетки) служит благоприятной средой для развития на его фоне злокачественных новообразований [2, 4]. Учитывая, что риск злокачественной транссормации существует, а наличие самого невуса сопровождается у пациентов проблемами эстетического характера, авторы считают целесообразным производить удаление NSJ у пациентов после полового созревания. Выбор метода удаления у пациентов молодого возраста достаточно широкий: кюретаж, каутеризация, криотерапия, фотодинамическая терапия, лазерная аблация, хирургическое иссечение. Опыт успешного применения $\mathrm{CO}_{2}$-лазера с хорошим косметическим эффектом описан у детей [14]. Этот

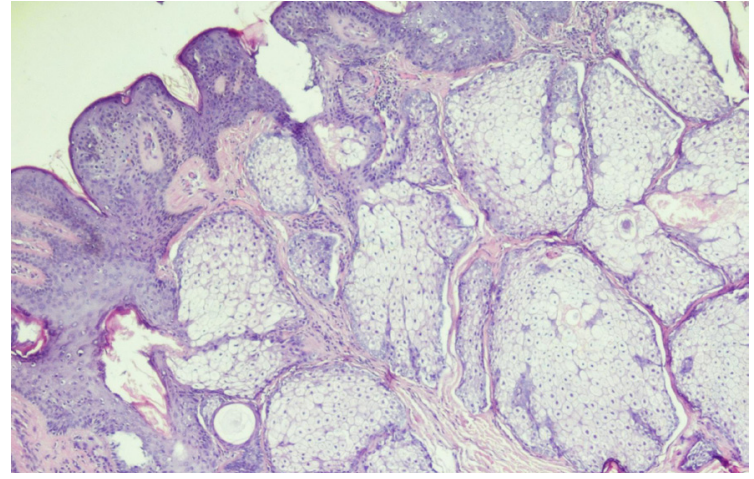

Рис. 6. Фрагмент кожи с субэпителиальной пролиферацией сальных желёз Окраска: гематоксилин-эозин; увеличение $\times 40$

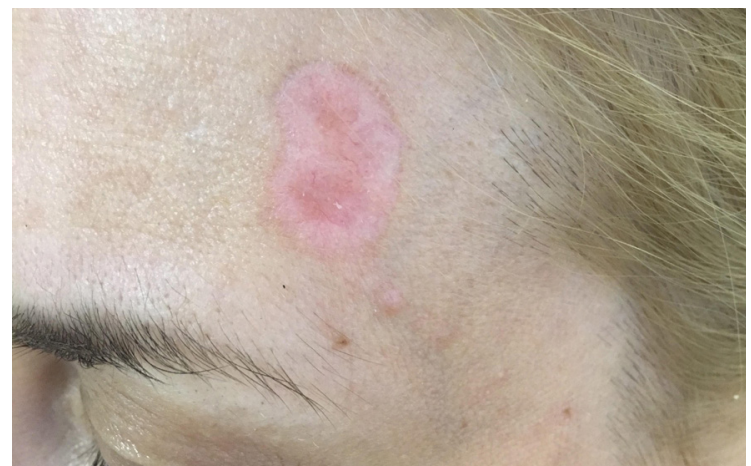

Рис. 7. Пациентка А., 30 лет. Формирование нормотрофического рубца после удаления $\mathrm{CO}_{2}$-лазером невуса Ядассона на коже лба

метод характеризуется высокой эффективностью, меньшим повреждением нормальных тканей и хорошим косметическим эффектом. У пациентов старше 50 лет удаление следует проводить радикальным хирургическим способом. В случае невозможности сделать это по каким-либо причинам показано постоянное динамическое наблюдение.

\section{ВЫВОДЫ}

Представленные клинические случаи демонстрируют хороший косметический эффект после удаления NSJ $\mathrm{CO}_{2}$-лазером. Данный метод может быть рекомендован

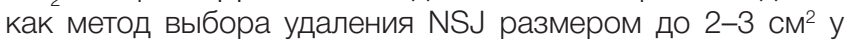
лиц молодого возраста.

\section{Литература}

1. Lantis S, Leyden J, Heaton C. Nevus sebaceous Jadassohn. Arch Dermatol 1968, 98: 117-23.

2. Молочков В. А., Марди Ш. К развитию базалиомы на фоне невуса сальных желёз Ядассона. Альманах клинической медицины. 2007; 15: 232-5.

3. Simi C, Rajalakshmi T, Correa M. Clinicopathologic analysis of 21 cases of nevus sebaceus: A retrospective study. Indian $J$ Dermatol Venereol Leprol. 2008; 74 (6): 625-7.

4. Alessi E, Sala F. Nevus sebaceus. A clinicopathologic study of its evolution. Am J Dermatopathol. 1986; 8 (1): 27-31.

5. Liu Y, Valdebran M, Chen J, Elbendary A, Wu F, Xu M. Nevus sebaceous of Jadassohn with eight secondary tumors of follicular, sebaceous, and sweat gland differentiation. Am J Dermatopathol. 2016; 38 (11): 861-6.

6. Jaqueti G, Requena L, Sánchez Yus E. Trichoblastoma is the most common neoplasm developed in nevus sebaceus of

Jadassohn. A clinicopathologic study of a series of 155 cases. Am J Dermatopathol. 2000; 22 (2): 108-18.

7. Pointdujour-Lim R, Marous MR, Satija CE, Douglass AM, Eagle RC, Shields CL. Cutaneous Horn of the Eyelid in 13 Cases. Ophthalmic Plastic and Reconstructive Surgery. 2017; 33 (4): 233-6.

8. Arvas L, Livaoglu M, Karacal N, Sozen E, Kara B. Giant cutaneous horn with naevus sebaceous. J Plast Reconstr Aesthet Surg. 2007; 60 (11): 1268-9.

9. Kamyab-Hesari K, Seirafi H, Jahan S, Aghzadeh N, Hejazi P, Azizpour A, et al. Nevus sebaceus: A clinicopathological study of 168 cases and review of the literature. Int J Dermatol. 2016; 55 (2): 193-200.

10. Westfried M, Mikhail GR. Multifocal Basal-Cell Carcinomas in a Nevus Sebaceus of Jadassohn. J Dermatol Surg Oncol. 1981; 7 (5): 420-2.

11. Idriss $\mathrm{MH}$, Elston DM. Secondary neoplasms associated with 
nevus sebaceus of Jadassohn: A study of 707 cases. J Am Academ Dermatol. 2014; 70 (2): 332-7.

12. Jardim MML, Souza BC, Fraga RC. Rare desmoplastic trichilemmoma associated with sebaceous nevus. Anais Brasileiros de Dermatogia. 2017; 92 (6): 836-7.

13. Liu Y, Valdebran M, Chen J, Elberdary A, Wu F, Xu M. Nevus
Sebaceous of Jadassohn wiht Eight Secondary Tumors of Follicular, Sebaceous, and Sweat Gland Differentiation. Am J Dermatopathol. 2016; 38 (11): 861-6.

14. Ashinoff R. Linear Nevus Sebaceus of Jadassohn Treated with the Carbon Dioxide Laser. Pediatr Dermatol. 1993; 10 (2):189-91.

\section{References}

1. Lantis S, Leyden J, Heaton C. Nevus sebaceous Jadassohn. Arch Dermatol 1968, 98: 117-23.

2. Molochkov VA, Mardi Sh. K razvitiju bazaliomy na fone nevusa sal'nyh zheljoz Jadassona. Al'manah klinicheskoj mediciny. 2007; 15: 232-5.

3. Simi C, Rajalakshmi T, Correa M. Clinicopathologic analysis of 21 cases of nevus sebaceus: A retrospective study. Indian $J$ Dermatol Venereol Leprol. 2008; 74 (6): 625-7.

4. Alessi E, Sala F. Nevus sebaceus. A clinicopathologic study of its evolution. Am J Dermatopathol. 1986; 8 (1): 27-31.

5. Liu Y, Valdebran M, Chen J, Elbendary A, Wu F, Xu M. Nevus sebaceous of Jadassohn with eight secondary tumors of follicular, sebaceous, and sweat gland differentiation. Am J Dermatopathol. 2016; 38 (11): 861-6.

6. Jaqueti G, Requena L, Sánchez Yus E. Trichoblastoma is the most common neoplasm developed in nevus sebaceus of Jadassohn. A clinicopathologic study of a series of 155 cases Am J Dermatopathol. 2000; 22 (2): 108-18.

7. Pointdujour-Lim R, Marous MR, Satija CE, Douglass AM, Eagle RC, Shields CL. Cutaneous Horn of the Eyelid in 13 Cases. Ophthalmic Plastic and Reconstructive Surgery. 2017; 33 (4): 233-6.

8. Arvas L, Livaoglu M, Karacal N, Sozen E, Kara B. Giant cutaneous

horn with naevus sebaceous. J Plast Reconstr Aesthet Surg. 2007; 60 (11): 1268-9.

9. Kamyab-Hesari K, Seirafi H, Jahan S, Aghzadeh N, Hejazi P, Azizpour A, et al. Nevus sebaceus: A clinicopathological study of 168 cases and review of the literature. Int J Dermatol. 2016; 55 (2): 193-200.

10. Westfried M, Mikhail GR. Multifocal Basal-Cell Carcinomas in a Nevus Sebaceus of Jadassohn. J Dermatol Surg Oncol. 1981; 7 (5): 420-2.

11. Idriss $\mathrm{MH}$, Elston DM. Secondary neoplasms associated with nevus sebaceus of Jadassohn: A study of 707 cases. J Am Academ Dermatol. 2014; 70 (2): 332-7.

12. Jardim MML, Souza BC, Fraga RC. Rare desmoplastic trichilemmoma associated with sebaceous nevus. Anais Brasileiros de Dermatogia. 2017; 92 (6): 836-7.

13. Liu Y, Valdebran M, Chen J, Elberdary A, Wu F, Xu M. Nevus Sebaceous of Jadassohn wiht Eight Secondary Tumors of Follicular, Sebaceous, and Sweat Gland Differentiation. Am J Dermatopathol. 2016; 38 (11): 861-6.

14. Ashinoff R. Linear Nevus Sebaceus of Jadassohn Treated with the Carbon Dioxide Laser. Pediatr Dermatol. 1993; 10 (2):189-91. 